www.jmscr.igmpublication.org

Impact Factor (SJIF): 6.379

Index Copernicus Value: 71.58

ISSN (e)-2347-176x ISSN (p) 2455-0450

crossref DOI: _https://dx.doi.org/10.18535/jmscr/v6i4.50

Journal Of Medical Science And Clinical Research

\title{
A Comparative Study of Wound Instillation with Different Concentration of Bupivacaine via Surgical Drain for Post-Operative Analgesia in Modified Radical Mastectomy
}

\author{
Authors \\ Dr Rajesh Kumar Meena, Dr Anita Pareek, Dr Kiwi Mantan, Dr Sangeeta Meena \\ Dr Priyanka Kumari
}

\begin{abstract}
Background \& Aim: In this randomized, controlled, double-blind study of wound instillation to compare with different concentration of bupivacaine via surgical drain in patient undergoing modified radical mastectomy would reduce the postoperative acute pain and would reduce amount of rescue analgesics used in postoperative period. Aim of the study is to evaluate the efficacy of bupivacaine for analgesia with different concentration and provide economical, safe and good analgesia.

Material and Method: Ninety patient undergoing elective modified radical mastectomy were randomized in to 3 groups. Following placing the surgical drain, Group A received no instillation. Group B and $C$ received bupivacaine $0.125 \%$ and $0.25 \%$ instillation via surgical drains. Pain was assessed using visual analog scale at fixed time interval and other side effects were noted for next $24 \mathrm{hrs}$. Statistical analysis was done by using SPSS version 21, INDOSTAT statistical analysis software.

Observations: No significant difference were seen in analgesic duration with higher concentration dosage of bupivacaine. The median pain level postoperatively were $4 \pm .5 \mathrm{hr}$ and $6 \pm 5 \mathrm{hr}$ in group B and $C$. ( $p$ value $<0.001)$

Conclusion: Higher concentration of Bupivacaine doesn't significantly improve the duration of pain control. Instead of potential dose related risks.

Keywords: wound instillation, Bupivacaine (0.125\% \& 0.25\%), Visual analogue scale (VAS).
\end{abstract}

\section{Introduction}

A Modified Radical Mastectomy is a procedure in which the entire breast is removed, including the skin, areola, nipple, and most axillary lymph nodes; the pectoralis major muscle is spared. Historically, a modified radical mastectomy was the primary method of treatment of breast cancer. As the treatment of breast cancer evolved, breast conservation has become more widely used. Mastectomy still remains a viable option for women with breast cancer.
However, pain after breast cancer surgery is a major problem and women undergoing mastectomy experience postoperative pain syndrome in approximately one half of all cases. Effective treatment of postoperative pain contributes to decreasing the rate of complications as emotional and physical suffering, sleep disturbance, cardiovascular side effects, increased oxygen consumption as well as the total cost of the operated patients. 
Local anaesthetic drugs have become increasingly popular because of their analgesic properties and lack of opioid- induced adverse effect for treating postoperative surgical pain. Instillation of local anaesthetic through axillary and chest drain, placed surgically, may provide a better analgesia. General anaesthesia is currently the standard technique used for surgical treatment of breast cancer. Increasing hospital costs have focused attention on reducing the length of hospital stay for these patients. However, the side effects and complications of general anaesthesia preclude ambulatory surgery for most patients undergoing breast surgery. ${ }^{1}$

Pre-emptive analgesia'-[analgesia administered before the painful stimulus occurs may prevent or substantially reduce subsequent pain or analgesic requirement] Effective pre-emptive analgesic technique use multiple pharmacological agents to reduce nociceptor activation, and inhibiting the production or activity of pain neurotransmitters. Pre-emptive analgesia can be administered via local wound infiltration applied in the area of the surgical incision in patients undergoing mastectomy for breast cancer would reduce postoperative acute pain and would reduce the amount of analgesic, but no decrease in postoperative pain score. $^{2}$

Post-incisional infiltration with bupivacaine provides improved postoperative pain relief and is cost-effective and shorten hospital stay. Infiltration of local anaesthetic along the line of incision is not recommended in malignant lesions, because of the fear of needle track seedlings and cutaneous spread of malignancy. Moreover, the tissue dissection extends beyond the surgical incision. ${ }^{3}$

Infiltration of local anaesthetics is an effective technique for controlling postoperative pain and the associated added costs are relatively low in relation to the total cost of mastectomy, therefore providing patients with a higher quality of care in the prevention of pain. ${ }^{4}$

Modified Radical Mastectomy (MRM) is the commonly used surgical procedure for operable breast cancer, which involves extensive tissue dissection. Therefore, wound instillation with local anaesthetic may provide better postoperative analgesia than infiltration along the line of incision. Bupivacaine instillation through surgical drains for postoperative analgesia in modified radical mastectomy is simple and effective means of providing good analgesia without any major side effects. ${ }^{5}$

We hypothesised that instillation with different concentration of bupivacaine through chest and axillary drains into the wound may provide postoperative analgesia and reduces the concentration related side effects.

- To evaluate the efficacy of bupivacaine in post-operative analgesia via Instillation through surgical drains in modified radical mastectomy.

- To observe the effect of different concentration of bupivacaine for postoperative analgesia and duration.

- To compare the post-operative analgesia and duration of different concentration of bupivacaine.

- To observe post-operative complications.

- To provide simple, effective and economically good analgesia with minimal or no side effect.

\section{Patients \& Methods}

This study was conducted on 90 cases in the department of Anaesthesiology, Sardar Patel medical college and associated group of Hospitals Bikaner after taking consent from institutional research board.

We included the Patients ranging between the age group 45 to 60 years belonging to American Society of Anaesthesiologists grade I and II, undergoing modified radical mastectomy under general anaesthesia. Randomization is done by sealed envelope technique. We randomised into 3 groups of 30 patients each and an effort were made that the group do not significantly differ with respect to age, weight and height. 
Patient with history of clinically significant cardiovascular, pulmonary, renal, neurologic disease, a history of chronic analgesic drug usage $>1$ month, History of coexisting disease. Allergic to anaesthetic drugs and Patient with major blood loss and unpredictable blood collection in drain were excluded.

On the day prior to surgery a thorough clinical examination of the patient was performed including general physical examination and systemic examination. All patients were explained about the anaesthetic technique and written informed consent was taken. Patient was kept NBM for 6 hours prior to surgery. Routine investigations was done. $\mathrm{HB} \%, \mathrm{BT}, \mathrm{CT}$, urine analysis, chest $\mathrm{X}$-ray, Blood urea, serum creatinine $\&$ fasting sugar. No specific investigation required pertaining to the study. Group 1: No instillation, Group 2: Bupivacaine $0.125 \%$, Group 3: Bupivacaine $0.25 \%$. At the end of surgical procedure, drain in the chest wall below the skin flap was placed by the surgeon before closing the surgical incision. The study drug was given in the drain. Group 1 patients received no instillation. Group 2 patients received $40 \mathrm{ml}$ bupivacaine $0.125 \%$. Group 3 patients received $40 \mathrm{ml}$ bupivacaine $0.25 \%$. After instillation of the study drug the drain was clamped for a period of 10 Min then clamp was released to allow the test solution into the negative pressure suction drain [Romovac].

Vitals recorded at following time interval

\begin{tabular}{|c|c|}
\hline T0 & After extubation \\
\hline T1 & After $2 \mathrm{hr}$ \\
\hline T2 & After $4 \mathrm{hr}$ \\
\hline T3 & After $6 \mathrm{hr}$ \\
\hline T4 & After $10 \mathrm{hr}$ \\
\hline T5 & After $14 \mathrm{hr}$ \\
\hline T6 & After $18 \mathrm{hr}$ \\
\hline
\end{tabular}

\section{Likert scale (for surgeon satisfaction)}

\begin{tabular}{|l|c|}
\hline 1 & Strongly disagree \\
\hline 2 & Disagree \\
\hline 3 & Neither agree nor disagree \\
\hline 4 & Agree \\
\hline 5 & Strongly agree \\
\hline
\end{tabular}

\section{Visual Analogue Scale VAS (0-10)}

VAS is a $10 \mathrm{~cm}$ horizontal line labelled as "No pain" at one end and "Worst Pain imaginable on the other end. Patient was asked to mark on the line where the pain lies.
- No pain

- 1 - 3 Mild pain

- 4-6 Moderate pain

- 7-9 Severe pain

- 10 - Worst pain

Data were expressed as mean values \pm SD Normality of distribution was assessed on the results, either parametric or nonparametric tests were performed. Normally distributed continuous data were analysed and compared using the ANOVA. Number of patients receiving "rescue" analgesia, number of analgesic demands was analysed by using $\chi$ test, Patient-generated VAS. An ordered categorical variable was analysed. Statistical analysis was performed using SPSS version 21, INDOSTAT software.

\section{Results}

Table I shows mean arterial pressure in Group I, II and III at different time interval T0, T1, T2, T3, T4, T5 and T6. On comparison difference was statistically insignificant between all three Groups. While the difference was found statistically significant at $\mathrm{T} 3$.

\begin{tabular}{|c|c|c|c|c|c|c|c|}
\hline \multirow{3}{*}{$\begin{array}{l}\text { TIME } \\
\text { INTERVAL } \\
\text { (HOURS) }\end{array}$} & \multicolumn{6}{|c|}{ GROUPS } & \multirow[t]{3}{*}{ CD } \\
\hline & \multicolumn{2}{|l|}{ I } & \multicolumn{2}{|l|}{ II } & \multicolumn{2}{|l|}{ III } & \\
\hline & MEAN & SD & MEAN & SD & MEAN & SD & \\
\hline T0 & 99.84 & 5.26 & 97.18 & 5.24 & 97.18 & 5.25 & 2.88 \\
\hline $\mathrm{T} 1$ & 95.63 & 5.17 & 92.84 & 5.05 & 95.11 & 4.86 & 2.75 \\
\hline $\mathrm{T} 2$ & 95.11 & 4.87 & 95.74 & 8.97 & 95.12 & 4.87 & 2.77 \\
\hline T3 & 100.22 & 4.92 & 99.88 & 5.14 & 100.22 & 4.92 & 2.73 \\
\hline T4 & 94.06 & 6.80 & 94.07 & 6.80 & 94.04 & 6.80 & 3.72 \\
\hline T5 & 100.22 & 4.90 & 97.18 & 5.26 & 94.06 & 6.80 & 2.94 \\
\hline T6 & 100.22 & 4.90 & 95.74 & 5.45 & 94.06 & 6.80 & 1.05 \\
\hline
\end{tabular}

Table II shows the mean time of onset of analgesia in three groups. It was earliest in group I as compare to group II and group III respectively. When we compared group II and III, it was highly significant in group II as per requirement of drug doses

\begin{tabular}{|c|c|c|c|c|c|c|}
\hline \multicolumn{7}{|c|}{ Groups } \\
\hline \multicolumn{3}{|c|}{ I } & \multicolumn{2}{|l|}{ II } & \multicolumn{2}{|c|}{ III } \\
\hline \multicolumn{2}{|c|}{$\begin{array}{c}\text { Onset of } \\
\text { analgesia(min) }\end{array}$} & $\%$ & $\begin{array}{c}\text { Onset of } \\
\text { analgesia(min) }\end{array}$ & $\%$ & $\begin{array}{r}\text { On } \\
\text { analg }\end{array}$ & $\%$ \\
\hline \multicolumn{2}{|c|}{3} & 50 & 9 & 40 & & 50 \\
\hline \multicolumn{2}{|c|}{4} & 33 & 10 & 20 & & 30 \\
\hline \multicolumn{2}{|c|}{5} & 17 & 9.5 & 30 & & 20 \\
\hline Mean & \multicolumn{2}{|c|}{3.66} & Mean & 9.4 & Mean & 9.4 \\
\hline \multirow[t]{2}{*}{ SD } & \multicolumn{2}{|c|}{0.74} & SD & 0.37 & SD & 0.43 \\
\hline & & \multicolumn{2}{|l|}{$\mathrm{P}$} & & \\
\hline \multicolumn{3}{|c|}{ Group I vs II } & \multicolumn{2}{|c|}{$<0.028$} & & \\
\hline \multicolumn{3}{|c|}{ Group I vs III } & \multicolumn{2}{|l|}{$<0.038$} & & \\
\hline \multicolumn{3}{|c|}{ Group II vs III } & \multicolumn{2}{|l|}{$<0.015$} & & \\
\hline
\end{tabular}


Table III shows the duration of analgesia in three groups. It was longer in group II and III compared to group I. On statistical comparison, the difference was found significant when compared to group I vs group II and group III, but it was highly significant when compared group II to group III.

\begin{tabular}{|c|c|c|c|c|c|c|}
\hline \multicolumn{7}{|c|}{ Groups } \\
\hline \multicolumn{2}{|l|}{ I } & \multicolumn{2}{|l|}{ II } & \multicolumn{3}{|c|}{ III } \\
\hline $\begin{array}{c}\text { Duration of } \\
\text { Analgesia(hrs) }\end{array}$ & $\%$ & $\begin{array}{c}\text { Duration Of } \\
\text { Analgesia(hrs) }\end{array}$ & $\%$ & \multicolumn{2}{|c|}{$\begin{array}{c}\text { Duration of } \\
\text { Analgesia(hrs) }\end{array}$} & $\%$ \\
\hline 1.5 & 10 & 4 & 10 & \multicolumn{2}{|l|}{5} & 20 \\
\hline 2 & 60 & 4.5 & 50 & \multicolumn{2}{|l|}{5.5} & 60 \\
\hline 2.5 & 40 & 5 & 40 & \multicolumn{2}{|l|}{6} & 20 \\
\hline Mean & 2.15 & Mean & 4.65 & Mean & & \\
\hline \multirow{2}{*}{\multicolumn{2}{|c|}{0.32}} & SD & 0.32 & SD & \multicolumn{2}{|c|}{0.31} \\
\hline & & \multicolumn{2}{|l|}{$\mathrm{P}$} & & & \\
\hline \multicolumn{2}{|c|}{ Group I vs II } & \multicolumn{2}{|l|}{$<0.032$} & & & \\
\hline \multirow{2}{*}{\multicolumn{2}{|c|}{$\begin{array}{l}\text { Group I vs III } \\
\text { Group II vs III }\end{array}$}} & \multirow{2}{*}{\multicolumn{2}{|c|}{$<0.048$}} & & & \\
\hline & & & $<0.001$ & & & \\
\hline
\end{tabular}

Table IV shows mean VAS score in Group I, II and III at different time interval T0, T1, T2, T3, $\mathrm{T} 4, \mathrm{~T} 5$ and T6. At time interval T2 it was found statistically significant.

\begin{tabular}{|l|c|c|c|c|c|c|c|}
\hline \multirow{2}{*}{$\begin{array}{l}\text { VTIME } \\
\text { INTERVAL } \\
\text { (HOURS) }\end{array}$} & \multicolumn{9}{|c|}{ I } & \multicolumn{2}{c|}{ II } & \multicolumn{2}{c|}{ III } & \multirow{2}{*}{ CD } \\
\cline { 2 - 8 } & MEAN & SD & MEAN & SD & MEAN & SD & \\
\hline T0 & 4.00 & 0.00 & 0.00 & 0.00 & 0.00 & 0.00 & \\
\hline T1 & 1.0 & 0.00 & 0.233 & 0.62 & 0.00 & 0.00 & 0.86 \\
\hline T2 & 2.00 & 0.00 & 3.10 & 0.30 & 2.03 & 0.31 & 0.131 \\
\hline T3 & 4.00 & 0.00 & 3.60 & 1.20 & 3.26 & 0.44 & 0.386 \\
\hline T4 & 2.06 & 0.34 & 0.10 & 0.30 & 2.93 & 1.77 & 0.552 \\
\hline T5 & 3.90 & 0.54 & 1.10 & 0.30 & 0.26 & 0.44 & 0.229 \\
\hline T6 & 1.00 & 0.00 & 2.20 & 0.60 & 1.26 & 0.44 & 0.225 \\
\hline
\end{tabular}

Table V shows the requirement of rescue analgesic in groups. The requirement of rescue analgesic is $100 \%$ in group I when compared to group II and III, while when we compared between II and III group requirement needed at time interval T2, T3 and T6

\begin{tabular}{|l|c|c|c|c|c|c|}
\hline \multirow{3}{*}{$\begin{array}{c}\text { Time } \\
\text { (hrs) }\end{array}$} & \multicolumn{6}{|c|}{ Groups } \\
\cline { 2 - 7 } & Analgesia(mg) & $\%$ & Analgesia(mg) & $\%$ & Analgesia(mg) & $\%$ \\
\hline T0 & + & 100 & - & - & - & - \\
\hline T1 & - & - & - & - & - & - \\
\hline T2 & - & - & + & 10 & - & - \\
\hline T3 & + & 100 & + & 90 & + & 20 \\
\hline T4 & - & - & - & - & + & 80 \\
\hline T5 & + & 100 & - & - & - & - \\
\hline T6 & - & - & + & 10 & - & - \\
\hline
\end{tabular}

Table VI shows distribution of patients according to satisfaction score. Mean satisfaction score in group I was $2.05 \pm 0.39$, in group II $4.20 \pm 0.52$ while in group III, 3.00 \pm 0.73 , All the difference were found statistically significant $(\mathrm{p}<0.001)$ on comparing group I Vs II, Group I Vs III and Group II Vs III.

\begin{tabular}{|c|c|c|c|c|c|c|c|c|}
\hline \multirow{3}{*}{$\begin{array}{l}\text { Satisfaction } \\
\text { score }\end{array}$} & \multicolumn{6}{|c|}{ Group } & \multirow{2}{*}{\multicolumn{2}{|c|}{ Total }} \\
\hline & \multicolumn{2}{|c|}{$\mathrm{I}$} & \multicolumn{2}{|c|}{ II } & \multicolumn{2}{|c|}{ III } & & \\
\hline & No. & $\%$ & No. & $\%$ & No. & $\%$ & No. & $\%$ \\
\hline 1 & 3 & 10 & 0 & - & 0 & - & 3 & 3.33 \\
\hline 2 & 24 & 80 & 0 & - & 6 & 20 & 30 & 33.3 \\
\hline 3 & 3 & 10 & 3 & 10 & 18 & 60 & 24 & 26.6 \\
\hline 4 & 0 & - & 18 & 60 & 6 & 20 & 24 & 26.6 \\
\hline 5 & 0 & - & 9 & 30 & 0 & - & 9 & 10 \\
\hline Total & 30 & 100 & 30 & 100 & 30 & 100 & 90 & 100 \\
\hline Mean & \multicolumn{2}{|c|}{2.05} & \multicolumn{2}{|c|}{4.20} & \multicolumn{2}{|c|}{3.00} & & \\
\hline SD & \multicolumn{2}{|c|}{0.39} & \multicolumn{2}{|c|}{0.52} & \multicolumn{2}{|c|}{0.73} & & \\
\hline & & & \multicolumn{2}{|c|}{$\mathrm{T}$} & \multicolumn{2}{|c|}{$\mathrm{P}$} & & \\
\hline \multicolumn{3}{|c|}{ Group I Vs II } & \multicolumn{2}{|c|}{14.681} & \multicolumn{2}{|c|}{$<0.001$} & & \\
\hline \multicolumn{3}{|c|}{ Group I Vs III } & \multicolumn{2}{|c|}{5.146} & \multicolumn{2}{|c|}{$<0.001$} & & \\
\hline \multicolumn{3}{|c|}{ Group II Vs III } & \multicolumn{2}{|c|}{6.000} & \multicolumn{2}{|c|}{$<0.001$} & & \\
\hline
\end{tabular}

Table VII shows in group I (6 patients had nausea and 3 patients had vomiting) and when we compared to group II and group III (only 2 patient in group II had nausea and no one had vomiting but in group III 4 patient had nausea and 2 patients had vomiting too).

\begin{tabular}{|c|c|c|c|c|c|c|}
\hline \multirow{3}{*}{ complications } & \multicolumn{6}{|c|}{ Groups } \\
\hline & \multicolumn{2}{|l|}{$\mathrm{I}$} & \multicolumn{2}{|l|}{ II } & \multicolumn{2}{|l|}{ III } \\
\hline & No. & $\%$ & No. & $\%$ & No. & $\%$ \\
\hline nausea & 6 & 20 & 2 & 6.66 & 4 & 13.33 \\
\hline vomiting & 3 & 10 & 0 & 0 & 2 & 6.66 \\
\hline No adverse effect & 21 & 70 & 28 & 93.33 & 24 & 80 \\
\hline Total & 30 & 100 & 30 & 100 & 30 & 100 \\
\hline
\end{tabular}

\section{Discussion}

Post-operative pain control is an essential component of care of the surgical patient. Inadequate pain control may result in increased incidence of a multitude of complications and also morbidity or mortality. The objectives of this study were to assess postoperative pain score, reduce the requirement of analgesic to decrease the adverse effective of analgesic while providing a good post-operative pain control.

\section{Time of onset of analgesia}

In our study, onset of analgesia in group II and group III are 8-10 min having mean value of 9 $\min +1 \mathrm{~min}$. while in group I the onset of analgesia is bit quicker 6-8 min having mean value of $7 \mathrm{~min}+1 \mathrm{~min}$ which is insignificant as we compare the rate of adverse effect and requirement of rescue analgesia. In year 2015, Dumlu et $\mathrm{al}^{6}$ studied the effect of bupivacaine and to compare the routes of administration of bupivacaine in the management of postoperative incision site pain after thyroidectomy. $0.25 \%$ bupivacaine was 
applied on the surgical area following thyroidectomy they concluded that Intraoperative local bupivacaine application is effective in decreasing postoperative pain in patients with thyroidectomy. In year 2008, Kryger et $\mathrm{al}^{7}$ investigated the analgesic effect and incidence of postoperative requirement of antiemetic while using a local anaesthetic pain pump and intravenous narcotics. Patients receiving a pain pump reported significantly lower pain scores on the day of surgery, as well as on the first and second postoperative days when compared with patients who did not $(\mathrm{P}<0.01)$. The amount of intravenous and oral narcotics used paralleled the reduction in pain $(\mathrm{P}<0.01)$, they concluded that there were fewer episodes of PONV and antiemetic's used in the patients receiving a pain pump $(\mathrm{P}<0.01)$. A postoperative local anaesthetic pain pump can reduce pain, narcotic use, and PONV in women undergoing breast reduction.

\section{Hemodynamic stability}

During our study we noticed insignificant change only in Group I (after giving intravenous tramadol) while in Group II and III there were no changes in systolic, diastolic and mean blood pressure. All the patients maintained the blood pressure within normal range.

\section{Duration of Analgesia}

The duration and quality of analgesia evidenced by change in VAS score was dose dependent. In group I after giving intravenous tramadol 100mg over 3 min quality was equivalent to instillation of bupivacaine via surgical drain. But the duration of analgesia in our study Group I ( $2+.5$ hours) is less compared to Group II (5+.5hours) and Group III (6+.5hours) which is significant in Group II and III when compared to Group I.Altuntas et $\mathrm{al}^{8}$ compared the efficacy of local anaesthetic infiltration to trocar wounds and intraperitoneally on postoperative pain. Patients were randomized into three groups by a closed envelope method: group I, trocar site local anaesthetic infiltration $(20 \mathrm{~mL}$ of $0.5 \%$ bupivacaine); group II, intraperitoneal local anaesthetic instillation $(20 \mathrm{~mL}$ of $0.5 \%)$ and group
III, control group (normal saline), among the three groups $(\mathrm{p} \geq 0.005)$. During all periods, VAS in group I was significantly lower than that in groups II and III ( $p<0.001)$. They concluded that Trocar site local anaesthetic infiltration is more effective for postoperative analgesia, easier to apply and safer than other analgesia methods. Cambell et $\mathrm{al}^{9}$ observed to infiltrate local anaesthetic in breast surgery. Patients were randomized to receive infiltration with bupivacaine $(0.25 \%)$ into the surgical wound (Group LA) or no infiltration. Analysis revealed Group LA used significantly less opioids than Group No LA during the first 48 $\mathrm{h}$ post-operative. They concluded that LA infiltration during breast surgery has a marked opioid sparing effect, which has significant patient benefits as well as reducing nursing workload and drug costs.

\section{Patient Satisfaction Score}

Evaluation of patient satisfaction with postoperative pain control guides quality improvement to strengthen the level of pain relief and improve care.

The patient satisfaction score in our study was good, mean satisfaction score in group was $2.05+0.39$, in group II $4.20+0.52$ while in group III 3.0+0.73. All the differences were found statically highly significant $(p<0.01)$ on comparing group I vs II, group I vs III and group II vs III. This correlates with the findings Mahabiret al $^{10}$ compared the postoperative analgesia with ketorolac and bupivacaine in breast augmentation patients. Normal saline, ketorolac alone $(30 \mathrm{mg})$, bupivacaine alone $(150 \mathrm{mg})$, or ketorolac and bupivacaine $(30 \mathrm{mg}$ and $150 \mathrm{mg}$ respectively) were placed into the implant pocket before implant insertion. The primary outcome was pain as measured by the visual analogue pain scale. They concluded that the ketorolac and bupivacaine patients spent less time in the recovery room and used fewer analgesics postoperatively than the other patients.

\section{Adverse effects / Complications}

No major adverse effects like restless, confusion, slurring of voice, seizures and slow heart rate 
were observed in patients who received bupivacain (plain) via surgical drain. Side effects like nausea and vomiting were observed in all three groups. Incidence of nausea and vomiting were found $20-25 \%, 3-5 \%$ and $10-20 \%$ respectively in Group I, II and III.

\section{Limitation of our study}

However, there are certain limitations of our study.

1. Small sample size and absence of long term follow up.

2. Study included only the procedure where post operatively surgical drain is compulsory.

\section{Summary}

The aim of our study was to evaluate the efficacy of bupivacaine in post-operative Analgesia via Instillation through surgical drains in modified radical mastectomy to observe the effect of different concentration of bupivacaine for postoperative analgesia and duration as well as minimise the drug related adverse effects

We conducted our study in 90 adult female patients belonging to American society of Anaesthesiologist's physical status of I and II grades were included in study. They randomised in to 3 groups of 30 patients each, I $(n=30)$, II $(\mathrm{n}=30)$, III $\quad(\mathrm{n}=30)$. Group1 received No instillation, Group 2 received Bupivacaine 0.125 $\%$ (plain) 40ml via surgical drain, and Group 3 received Bupivacaine $0.25 \%$ (plain) $40 \mathrm{ml}$.

Vital parameters were noted at different time intervals and tabulated in observations. The data were analysed using appropriate statistical methods and we arrived at the following results:-

Onset of analgesia in group II and group III are 810 min having mean value of $9 \mathrm{~min}+1 \mathrm{~min}$. while in group I the onset of analgesia is bit quicker 6-8 min having mean value of $7 \mathrm{~min}+1 \mathrm{~min}$ which is insignificant as we compare the rate of adverse effect and requirement of rescue analgesia.

We noticed insignificant change only in Group I (after giving intravenous tramadol) while in Group
II and III there were no changes in systolic, diastolic and mean blood pressure. All the patients maintained the blood pressure within normal range.

The duration and quality of analgesia evidenced by change in VAS score was dose dependent. In group I after giving intravenous tramadol 100mg over 3 min quality was equivalent to instillation of bupivacaine via surgical drain. But the duration of analgesia in our study Group I ( $2+.5$ hours) is less compared to Group II (5+.5hours) and Group III $(6+.5$ hours $)$ which is significant in Group II and III when compared to Group I. No major significant difference was seen in analgesic duration with higher concentration dosage of bupivacaine. The median pain level postoperatively were $5 \mathrm{hr}$ and $6 \mathrm{hr}$ in group II and III.

The patient satisfaction score in our study was good, mean satisfaction score in group was $2.05+0.39$, in group II $4.20+0.52$ while in group III 3.0+0.73. All the differences were found statically highly significant $(\mathrm{p}<0.01)$ on comparing group I vs II, group I vs III and group II vs III.

No major adverse effects like restless, confusion, slurring of voice, seizures and slow heart rate were observed in patients who received bupivacain (plain) via surgical drain. Side effects like nausea and vomiting were observed in all three groups. Incidence of nausea and vomiting were found $20-25 \%, 3-5 \%$ and $10-20 \%$ respectively in Group I, II and III.

- Our results were in accordance to most of the previous studies conducted and supported that wound instillation with bupivacaine is a simple and effective means of providing good analgesia without any major side effects.

\section{Conclusions}

From this study the following conclusions can be drawn:

- Application of bupivacaine via surgical drain post modified radical mastectomy significant decrease early post-operative pain. The requirement of intravenous 
analgesic decreased and concomitant decrease in nausea and sedation.

- Use of bupivacaine in early post-operative period shorten the hospital stay and it provides a cost-effective benefit.

- Higher concentration of Bupivacaine doesn't significantly improve the duration of pain control. Instead of potential dose related risks.

\section{Reference}

1. Culliford AT 4th, Spector JA, Flores RL, Louie O, Choi M, Karp NS. Intraoperative Sensorcaine significantly improves postoperative pain management in outpatient reduction mammaplasty. Plast Reconstr Surg 2007; 120:840-4.

2. Zielinski J1, Jaworski R, Smietanska I, Irga N, Wujtewicz M, Jaskiewicz J. A randomized, double-blind, placeco controlled trail of pre-emptive analgesia with bupivacaine in patients undergoing mastectomy for carcinoma of the breast. Med SciMonit. 2011 Oct; 17(10):CR58997.

3. Lu TJ1, Chen JH, Hsu HM, Wu CT, Yu JC. Efficiency of infiltration with bupivacain after modified radical mastectomy. ActaChir Belg. 2011 NovDec; 111(6):360-3.

4. Ferreira Laso L1, López Picado A, Antoñanzas Villar F, Lamata de la Orden L, Ceballos Garcia M, IbañezLópez C, PipaonRuilope L, Lamata Hernandez F, Valero Martinez C, Aizpuru F, Hernandez Chaves R. Clin Drug Investig. Costeffectiveness analysis of levobupivacaine $0.5 \%$, a local anesthetic, infusion in the surgical wound after modified radical mastectomy. 2015 Sep; 35(9):575-82. doi: 10.1007/s40261-015-0316-4.
5. Jonnavithula N1, Khandelia H1, Durga P1, Ramachandran G1. Role of wound instillation with bupivacaine through surgical drains for postoperative analgesia in modified radical mastectomy. Indian $\mathbf{J}$ Anaesth. 2015 Jan; 59(1):15-20. doi: 10.4103/0019-5049.149443.

6. Dumlu EG, Tokae M, Oeal H. Local bupivacaine for postoperative pain management in the thyroidectomised patient: A prospective and controlled clinical study. Ulus CerrahiDerg. 2015;32(3):173-7

7. Kryger ZB1, Rawlani V, Lu L, Fine NA. Decreased postoperative pain, narcotic, and antiemetic use after breast reduction using a local anesthetic pain pump. Ann Plast Surg. 2008 Aug; 61(2):147-52. doi: 10.1097/SAP.0b013e31815a23ef.

8. Altuntus G, Akkaya OT, Ozkan. Comparision of intraabdominal and trocar site local anaesthetic infiltration on postoperative analgesia after laparoscopic cholecystectomy. Turk J Aanaesthesiol Reanim 2016;10.5152/TJAR

9. Campbell I1, Cavanagh S, Creighton J, French R, Banerjee S, Kerr E, Shirley R. To infiltrate or not? Acute effects of local anaesthetic in breast surgery. ANZ J Surg. 2015 May; 85(5):353-7.

10. Mahabir RC1, Peterson BD, Williamson JS, Valnicek SM, Williamson DG, East WE. Locally administered ketorolac and bupivacaine for control of postoperative pain in breast augmentation patients. Plast Reconstr Surg. 2004 Dec; 114(7): 1910-6. 